\section{Metal-Free "Click" Chemistry: Efficient Polymer Modification via 1,3-Dipolar Cycloaddition of Nitrile Oxides and Alkynes}

\author{
Ishwar Singh, ${ }^{\dagger}$ Zoya Zarafshani, ${ }^{\dagger}$ Jean-François Lutz, ${ }^{*},{ }^{\star}$ and \\ Frances Heaney,
}

${ }^{\dagger}$ Department of Chemistry, National University of Ireland, Maynooth, Co. Kildare, Republic of Ireland, and Research Group Nanotechnology for Life Science, Fraunhofer Institute for Applied Polymer Research, Geiselbergstrasse 69, Potsdam 14476, Germany

Received June 29, 2009

Revised Manuscript Received July 1, 2009

Polymer chemistry, probably more than any other chemical discipline, relies on highly efficient organic reactions. ${ }^{1}$ Indeed, typical macromolecular reactions such as polymer growth (i.e., chain- or step-growth), polymer modification (i.e side-chains or chain-ends) and chain-chain coupling (i.e., block copolymer synthesis, bioconjugation) generally require high-yield and highly specific chemical reactions. ${ }^{2}$ In that context, it comes as no surprise that modular reactions of the "click"-type ${ }^{3}$ have recently been gaining popularity in polymer science. For instance, more than 300 articles, describing the relevance of copper-catalyzed azide/alkyne cycloadditions (CuAAC) in polymer synthesis, have been published within the last five years. ${ }^{4}$ These archetypal "click" reactions open multiple possibilities in terms of macromolecular engineering. ${ }^{5}$

Yet, in some particular cases (e.g., bioconjugation with oligonucleotides or polysaccharides; modifications of living cells), copper catalysis was found to be an issue. ${ }^{6}$ Thus, within the past few years, the search for metal-free "click" reactions was intensified. For example, Bertozzi and co-workers reported an elegant strain-promoted approach for performing azide-alkyne cycloadditions in the absence of any transition metal. ${ }^{7}$ These reactions are bio-orthogonal and proceed generally in high yields. ${ }^{6}$ In addition, several other reactions such as thiol-ene addition, ${ }^{8}$ tandem $[3+2]$-cycloaddition-retro-Diels-Alder, ${ }^{9}$ cycloaddition of nitrones and maleimides, ${ }^{10}$ hetero Diels-Alder cycloadditions, ${ }^{11}$ and nucleophilic substitution of pentafluorostyrene ${ }^{12}$ have been described. These interesting reactions broaden the palette of available "click" tools for polymer synthesis.

In the present communication the isoxazole generating 1,3dipolar cycloaddition of nitrile oxides and alkynes was investigated (Scheme 1). Synthetically this is an interesting option, and further, the isoxazole ring, present in numerous bioactive compounds, has many possible modes of action with biological molecules. ${ }^{13}$ Similarly to the azide/alkyne cycloaddition, this reaction belongs to the general category of Huisgen cycloadditions. ${ }^{14}$ Yet, in the absence of any transition-metal catalyst, nitrile oxide/alkyne cycloadditions seem more advantageous than their azide/alkyne counterparts. Indeed, these reactions can be performed at relatively mild temperatures and are usually highly regioselective. ${ }^{13,15,16}$ If needed, these cycloadditions can also be efficiently catalyzed by copper- or ruthenium-based complexes. Fokin and co-workers recently demonstrated that interesting features such as ultrafast kinetics or "on demand" regiospecificity

*Corresponding author. E-mail: lutz@iap.fhg.de.
Scheme 1. General Scheme for the 1,3-Dipolar Cycloaddition of Nitrile Oxides and Alkynes

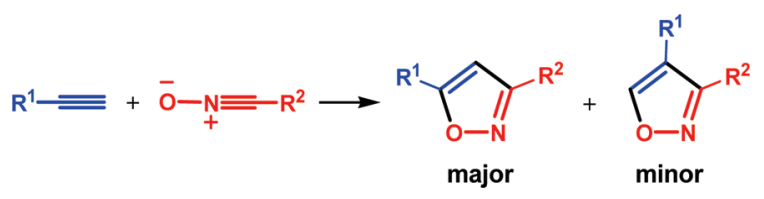

can be attained with appropriate catalysts. ${ }^{17}$ Nevertheless, almost all the characteristics of a "click"-reaction" ${ }^{3}$ can be met by uncatalyzed nitrile oxide/alkyne cycloadditions as recently demonstrated in the preparation of isoxazole modified oligonucleotides $^{18}$ and steroidal glycoconjugates. ${ }^{16}$ Thus, these promising reactions were studied herein for modifying the chain-ends of synthetic polymers.

Well-defined $\alpha-\omega$-telechelic model polymers were prepared by atom transfer radical (co)polymerization (ATRP) of oligo(ethylene glycol methacrylate)s. We previously evidenced that this particular class of monomers allow the construction of interesting water-soluble macromolecules. ${ }^{19}$ For instance, thermoresponsive polymers exhibiting a lower critical solution temperature (LCST) in water or physiological media can be easily prepared by copolymerization of short oligo(ethylene glycol methacrylate)s. ${ }^{20}$

The $\alpha$-alkyne functional polymers $\mathbf{P} 1$ and $\mathbf{P 2}$ (Figure 1) were synthesized via solution ATRP of oligo(ethylene glycol methacrylate)s initiated by a trimethylsilyl-protected alkyne initiator and subsequent deprotection. ${ }^{21}$ The formed copolymers were characterized by ${ }^{1} \mathrm{H}$ NMR spectroscopy, SEC and turbidimetry. The copolymer $\mathbf{P 1}$ exhibited a number average molecular weight of $15000 \mathrm{~g} \cdot \mathrm{mol}^{-1}$, a narrow molecular weight distribution $\left(M_{\mathrm{w}} / M_{\mathrm{n}}=1.18\right)$ and a cloud point at $39^{\circ} \mathrm{C}$ in pure water. The homopolymer $\mathbf{P} 2$ also exhibited a well-defined molecular structure $\left(M_{\mathrm{n}}=10000 \mathrm{~g} \cdot \mathrm{mol}^{-1} ; M_{\mathrm{w}} / M_{\mathrm{n}}=1.12\right)$. Moreover, for both samples, ${ }^{1} \mathrm{H}$ NMR spectral data confirmed the presence of $\alpha$-alkyne end-groups. In particular, for $\mathbf{P 1}$, diagnostic signals for the methylene protons $\mathrm{H}_{\mathrm{b}}$ and the alkyne proton $\mathrm{H}_{\mathrm{a}}$ appeared at $4.61 \mathrm{ppm}$ and $2.46 \mathrm{ppm}$ respectively (Figure 2 and ESI).

The hypothesis that nitrile oxide-alkyne click chemistry offers a robust tool for chain-end polymer functionalization was tested on the polymers $\mathbf{P 1}$ and $\mathbf{P 2}$. A range of low molecular weight nitrile oxides were used for the 1,3-dipolar cycloaddition. In all cases, the nitrile oxide was prepared in situ from the oxime precursor (Figure 1) and chloramine-T was selected as the dipole

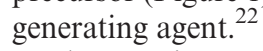

The reactions were conducted at room temperature, under atmospheric conditions, in aqueous solvents. After cycloaddition and purification, the modified polymers were characterized using ${ }^{1} \mathrm{H}$ NMR spectroscopy, SEC and turbidimetry. In all cases, nearly quantitative reaction yields were obtained (Table 1). Indeed, the characteristic proton of the alkyne function disappeared in all NMR spectra and was replaced by new $\alpha$-chain-end signals (Figure 2 and ESI). For instance, characteristic signals of the 3,5-disubstituted isoxazole moiety could be observed in all spectra with the 4-H ring proton resonating at approximately $6.50 \mathrm{ppm}\left(\mathrm{d}_{4}\right.$ in Figure 2$)$ and the adjacent methylene protons at $5.20 \mathrm{ppm}$. Significantly, in all cases, the ${ }^{1} \mathrm{H}$ NMR spectra of the reaction products failed to provide evidence for the formation of any of the regioisomeric 3,4-disubstituted isoxazole.

Thus, only one signal is observed for the methylene protons adjacent to the isoxazole ring and while it could be argued that the 


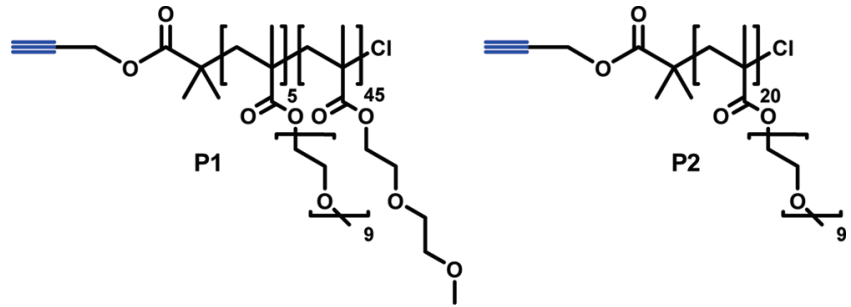<smiles>O=Cc1ccccc1</smiles>

1<smiles>N=Cc1c2ccccc2cc2ccccc12</smiles><smiles>ON=Cc1ccccc1F</smiles>

2

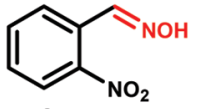

3
Figure 1. Molecular structures of the alkyne-functionalized polymers used in this study (top) and of the oximes used as nitrile oxide precursors (bottom).
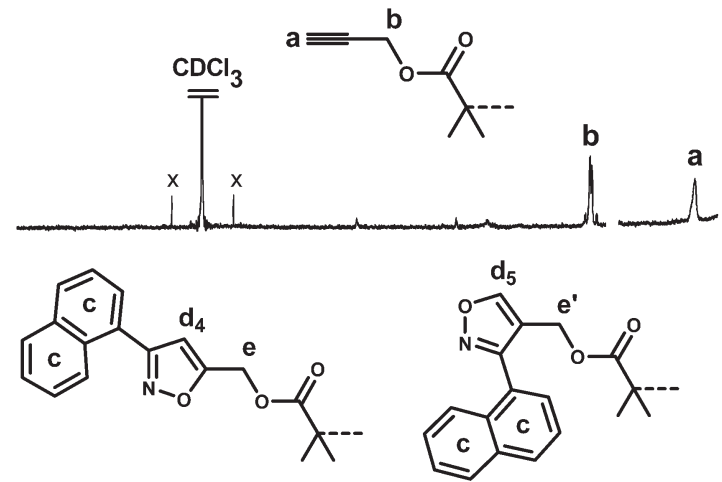

3,5-isomer

3,4-isomer (not detected)

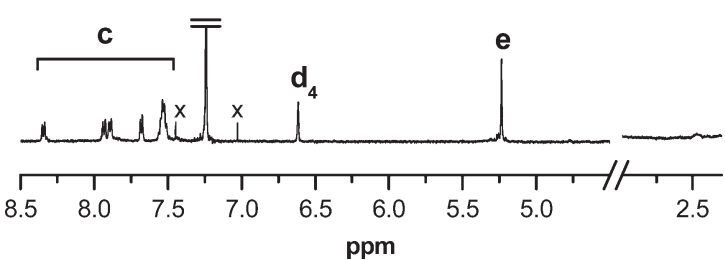

Figure 2. $500 \mathrm{MHz}{ }^{1} \mathrm{H}$ NMR spectra (zoom of the regions $8.50-4.50$ ppm and 2.99-2.30 ppm) recorded in $\mathrm{CDCl}_{3}$ for the polymer $\mathbf{P 1}$ before (top) and after reaction (bottom) with the nitrile oxide derived from 1-naphtaldehyde oxime 5 (Polymer P1-5 in Table 1).

Table 1. "Click" Functionalization of Poly(oligo ethylene glycol methacrylates) by 1,3-Dipolar Cycloaddition of Nitrile Oxides and Alkynes $^{a}$

\begin{tabular}{llccc}
\hline $\begin{array}{l}\text { alkyne- } \\
\text { polymer }\end{array}$ & $\begin{array}{c}\text { nitrile oxide } \\
\text { precursor }\end{array}$ & $\begin{array}{c}\text { functionalized } \\
\text { polymer }\end{array}$ & yield $^{b}(\%)$ & $\begin{array}{c}\text { formed } \\
\text { isomer }\end{array}$ \\
\hline P1 & $\mathbf{1}$ & $\mathbf{P 1 - 1}$ & $>99$ & 3,5 \\
P2 & $\mathbf{1}$ & $\mathbf{P 2 - 1}$ & 95 & 3,5 \\
P1 & $\mathbf{2}$ & $\mathbf{P 1 - 2}$ & 99 & 3,5 \\
P1 & $\mathbf{3}^{c}$ & $\mathbf{P 1 - 3}$ & 95 & 3,5 \\
P1 & $\mathbf{4}$ & $\mathbf{P 1 - 4}$ & 95 & 3,5 \\
P1 & $\mathbf{5}$ & $\mathbf{P 1 - 5}$ & 98 & 3,5
\end{tabular}

${ }^{a}$ Experimental conditions: room temperature, chloramine-T, EtOH: $4 \%$ aqueous $\mathrm{NaHCO}_{3} 1: 1,16 \mathrm{~h} .{ }^{b}$ Estimated from the ${ }^{1} \mathrm{H}$ NMR spectra of the purified polymers. ${ }^{c}$ A second dose of oxime and chloramine-T was added after the first $12 \mathrm{~h}$, total reaction time $24 \mathrm{~h}$ methylene protons of the 3,5- and 3,4-isomers resonate as a single peak at $5.20 \mathrm{ppm}$, this scenario is unlikely. Further, the $5-\mathrm{H}$ isoxazole ring proton $\left(\mathrm{d}_{5}\right.$ in Figure 2$)$ would be expected to resonate somewhere in the region of $7.50-8.50 \mathrm{ppm}^{17,23}$ Again, it could be construed that in some spectra this signal could possibly be masked by other aromatics signals. Significantly, in all spectra, the relative integrals of the signals representing the 4$\mathrm{H}$-isoxazole proton $\left(\mathrm{d}_{4}\right)$ and the methylene protons were in the expected $1 \mathrm{H} / 2 \mathrm{H}$ ratio.

Hence, these experimental results suggest that the cycloaddition reaction is highly regioselective and possibly regiospecific. Nevertheless, it should not be ruled out that a small fraction of regioisomeric 3,4-disubstituted isomer was formed in these experiments. However, if existing, these structures cannot be detected with standard polymer analytics. In addition, SEC and turbidimetry measurements confirmed that the properties of the polymers $\mathbf{P 1}$ and $\mathbf{P 2}$ were unchanged after nitrile oxide/alkyne cycloaddition. Before and after modification, the polymers exhibited the same molecular weight, molecular weight distribution and aqueous properties. ${ }^{24}$

In conclusion, the 1,3-dipolar cycloaddition of nitrile oxides and alkynes seems to be an efficient "metal-free" tool for functionalizing well-defined biocompatible polymers. Indeed, at room temperature, in polar medium, and in the absence of transition metal catalyst, these reactions proceed in high yields and are highly regiospecific. Hence, these cycloaddition appear as promising options for macromolecular engineering and polymer bioconjugation.

Acknowledgment. Financial support from the German Research Foundation (DFG, Sfb 448) and from the Science Foundation of Ireland (Programme code 05/PICA/B838) is gratefully acknowledged.

Supporting Information Available: Text giving a full experimental section and Figure S1, showing the $500 \mathrm{MHz}{ }^{1} \mathrm{H}$ NMR spectrum of $\mathbf{P 1}$. This material is available free of charge via the Internet at http://pubs.acs.org.

\section{References and Notes}

(1) Hawker, C. J.; Wooley, K. L. Science 2005, 309, 1200-1205.

(2) (a) Hawker, C. J.; Fokin, V. V.; Finn, M. G.; Sharpless, K. B. Aust. J. Chem. 2007, 60, 381-383. (b) Lutz, J.-F.; Schlaad, H. Polymer 2008, 49, 817-824. (c) Theato, P. J. Polym. Sci. Part A: Polym. Chem. 2008, 46, 6677-6687.

(3) Kolb, H. C.; Finn, M. G.; Sharpless, K. B. Angew. Chem., Int. Ed. 2001, 40, 2004-2021.

(4) (a) Lutz, J.-F. Angew. Chem., Int. Ed. 2007, 46, 1018-1025. (b) Fournier, D.; Hoogenboom, R.; Schubert, U. S. Chem. Soc. Rev. 2007, 8, 1369-1380. (c) Binder, W. H.; Sachsenhofer, R. Macromol. Rapid Commun. 2007, 28 (1), 15-54.

(5) Some examples of utilization of CuAAC in polymer chemistry (nonexhaustive list): (a) Wu, P.; Feldman, A. K.; Nugent, A. K.; Hawker, C. J.; Scheel, A.; Voit, B.; Pyun, J.; Frechet, J. M. J.; Sharpless, K. B.; Fokin, V. V. Angew. Chem., Int. Ed. 2004, 43, 3928-3932. (b) Lutz, J.-F.; Börner, H. G.; Weichenhan, K. Macromol. Rapid Commun. 2005, 26, 514-518. (c) Malkoch, M.; Schleicher, K.; Drockenmuller, E.; Hawker, C. J.; Russell, T. P.; Wu, P.; Fokin, V. V. Macromolecules 2005, 38, 3663-3678. (d) Sumerlin, B. S.; Tsarevsky, N. V.; Louche, G.; Lee, R. Y.; Matyjaszewski, K. Macromolecules 2005, 38, 7540-7545. (e) Lutz, J.-F.; Börner, H. G.; Weichenhan, K. Macromolecules 2006, 39, 6376-6383. (f) Vogt, A. P.; Sumerlin, B. S. Macromolecules 2006, 39, 5286-5292. (g) Agut, W.; Taton, D.; Lecommandoux, S. Macromolecules 2007, 40, 5653-5661. (h) Lutz, J.-F.; Börner, H. G.; Weichenhan, K. Aust. J. Chem. 2007, 60, 410413. (i) Binauld, S.; Damiron, D.; Hamaide, T.; Pascault, J.-P.; Fleury, E.; Drockenmuller, E. Chem. Commun. 2008, 4138-4140. (j) Fournier, D.; Du Prez, F. Macromolecules 2008, 41, 4622.

(6) (a) Lutz, J.-F. Angew. Chem., Int. Ed. 2008, 47, 2182-2184. (b) Becer, C. R.; Hoogenboom, R.; Schubert, U. S. Angew. Chem., Int. Ed. Engl. 2009, 48, 4900-4908. (c) Lallana, E.; Fernandez-Megia, E.; Riguera, R. J. Am. Chem. Soc. 2009, 131, 5748-5750. 
(7) (a) Agard, N. J.; Prescher, J. A.; Bertozzi, C. R. J. Am. Chem. Soc. 2004, 126, 15046-15047. (b) Johnson, J. A.; Baskin, J. M.; Bertozzi, C. R.; Koberstein, J. T.; Turro, N. J. Chem. Commun. 2008, 3064-3066.

(8) (a) Gress, A.; Volkel, A.; Schlaad, H. Macromolecules 2007, 40, 7928-7933. (b) Killops, K. L.; Campos, L. M.; Hawker, C. J. J. Am. Chem. Soc. 2008, 130, 5062-5064.

(9) van Berkel, S. S.; Dirks, A. J.; Debets, M. F.; van Delft, F. L.; Cornelissen, J. J. L. M.; Nolte, R. J. M.; Rutjes, F. P. J. T. ChemBioChem 2007, 8, 1504-1508.

(10) Vretik, L.; Ritter, H. Macromolecules 2003, 36, 6340-6345.

(11) Inglis, A. J.; Sinnwell, S.; Stenzel, M. H.; Barner-Kowollik, C. Angew. Chem., Int. Ed. 2009, 48, 2411-2414.

(12) Ott, C.; Hoogenboom, R.; Schubert, U. S. Chem. Commun. 2008, 3516-3518.

(13) Coutouli-Argyropoulou, E.; Lianis, P.; Mitakou, M.; Giannoulis, A.; Nowak, J. Tetrahedron 2006, 62, 1494-1501.

(14) Huisgen, R. Angew. Chem., Int. Ed. Engl. 1963, 2, 565-598.

(15) (a) Shang, Y.-J.; Wang, Y.-G. Tetrahedron Lett. 2002, 43, 2247-2249.

(b) Pinho e Melo, T. M. V. D. Curr. Org. Chem. 2005, 9, 925-958.

(c) Deng, B.-L.; Hartman, T. L.; Buckheit, R. W.; Pannecouque, C.; De Clercq, E.; Cushman, M. J. Med. Chem. 2006, 49, 5316-5323.

(16) (a) Wankhede, K. S.; Vaidya, V. V.; Sarang, P. S.; Salunkhe, M. M.; Trivedi, G. K. Tetrahedron Lett. 2008, 49, 2069-2073.
(17) (a) Himo, F.; Lovell, T.; Hilgraf, R.; Rostovtsev, V. V.; Noodleman, L.; Sharpless, K. B.; Fokin, V. V. J. Am. Chem. Soc. 2005, 127, 210 216. (b) Grecian, S.; Fokin, V. V. Angew. Chem., Int. Ed. 2008, 47, 82858287.

(18) (a) Singh, I.; Vyle, J. S.; Heaney, F. Chem. Commun. 2009, 32763278. (b) Gutsmiedl, K.; Wirges, C. T.; Ehmke, V.; Carell, T. Org. Lett. 2009, 11, 2405-2408.

(19) Lutz, J.-F. J. Polym. Sci. Part A: Polym. Chem. 2008, 46, 34593470 .

(20) (a) Lutz, J.-F.; Akdemir, O.; Hoth, A. J. Am. Chem. Soc. 2006, 128, 13046-13047. (b) Lutz, J.-F.; Hoth, A. Macromolecules 2006, 39, 893896. (c) Lutz, J.-F.; Andrieu, J.; Üzgün, S.; Rudolph, C.; Agarwal, S. Macromolecules 2007, 40 (24), 8540-8543.

(21) (a) Opsteen, J. A.; van Hest, J. C. M. Chem. Commun. 2005, 57-59. (b) Zarafshani, Z.; Akdemir, Ö.; Lutz, J.-F. Macromol. Rapid Commun. 2008, 29, 1161-1166.

(22) Hassner, A.; Rai, K. M. L. Synthesis 1989, 57-59.

(23) Lee, C. K. Y.; Easton, C. J.; Gebara-Coghlan, M.; Radom, L.; Scott, A. P.; Simpson, G. W.; Willis, A. C. J. Chem. Soc., Perkin Trans. 2 2002, 2031-2038.

(24) The cloud-points observed in pure water for the polymers derived form P1 varied slightly $\left( \pm 1^{\circ} \mathrm{C}\right)$ depending on the type of modified chain-ends. 